\title{
Methodology Report \\ Detection of GAD65 Autoreactive T-Cells by HLA Class I Tetramers in Type 1 Diabetic Patients
}

\author{
Laura Giuliani, ${ }^{1}$ Raffaella Mele, ${ }^{1}$ Monica Di Giovine, ${ }^{1}$ Laura Altieri, ${ }^{1}$ Antonino Crinò, ${ }^{2}$ \\ Lucilla Ravà, ${ }^{3}$ and Alessandra Fierabracci ${ }^{1}$
}

\author{
${ }^{1}$ Autoimmunity and Organ Regeneration Laboratory, Children's Hospital Bambino Gesù, Research Institute (IRCCS), \\ Piazza S. Onofrio 4, 00165 Rome, Italy \\ ${ }^{2}$ Unit of Pediatric Autoimmune Endocrine Diseases, Children's Hospital Bambino Gesù, Research Institute (IRCCS), \\ Piazza S. Onofrio 4, 00165 Rome, Italy \\ ${ }^{3}$ Department of Epidemiology, Children's Hospital Bambino Gesù, Research Institute (IRCCS), \\ Piazza S. Onofrio 4, 00165 Rome, Italy
}

Correspondence should be addressed to Alessandra Fierabracci, fierabracci@opbg.net

Received 23 April 2009; Revised 30 July 2009; Accepted 30 August 2009

Recommended by Marija Mostarica-Stojković

Type 1 diabetes (T1D) is an autoimmune disease, in which pancreatic $\beta$ cells are destroyed in genetically predisposed individuals. While the direct contribution of autoantibodies to the disease pathogenesis is controversial, it is generally recognised that the mechanism of $\beta$ cell destruction is mediated by autoreactive $\mathrm{T}$ cells that had escaped the thymic selection. We aimed to design a method to detect circulating CD8+ T cells autoreactive against an epitope of the glutamic acid decarboxylase autoantigen, isoform 65 (GAD65) ex vivo in T1D patients by using HLA class I tetramers. Low frequencies of GAD65 peptide-specific CD8+ cytotoxic T lymphocytes were detected in peripheral blood lymphocytes (PBMC) of normal controls after GAD65 peptide-specific stimulation. Conversely, their frequencies were significantly higher than in controls in PBMC of T1D patients after GAD65 peptide stimulation. These preliminary data are encouraging in order to develop a reliable assay to be employed in large-scale screening studies.

Copyright (C) 2009 Laura Giuliani et al. This is an open access article distributed under the Creative Commons Attribution License, which permits unrestricted use, distribution, and reproduction in any medium, provided the original work is properly cited.

\section{Introduction}

T1D is a chronic autoimmune disease where CD4+ and $\mathrm{CD} 8+\mathrm{T}$ cells recognizing islet autoantigens are likely the mediators of selective destruction of pancreatic islet beta cells [1]. Although direct demonstration of the prominent role of $\mathrm{T}$ cells in the disease progression is provided only in animal models, the preclinical period of the disease in humans is marked by the presence of circulating islet-related autoantibodies to beta cell antigens including insulin, glutamic acid decarboxylase (GAD), isoforms GAD65 and GAD67, the insulinoma-associated antigen (IA2)/tyrosine phosphataselike molecule, IA- $2 \beta$ or phogrin, and proinsulin [1].

From the 1990s onwards several laboratories produced an increasing number of reports regarding the detection of $\mathrm{T}$ cells directed against these antigens in the peripheral blood. The first attempts employed $\left[{ }^{3} \mathrm{H}\right]$ thymidine incorporation/proliferation assays setup with PBMC of
T1D patients (at onset or long-standing) and their "highrisk" ( $\mathrm{ICA}^{+}$) or "low-risk" (ICA-) first degree relatives [2]. Subsequently, ELISPOT assays were implemented for measuring cell-mediated immune (CMI) responses in T1D [3-5] and immunoblot assays [6]. Costimulatory antiCD28 antibodies were shown to enhance autoreactive $\mathrm{T}$ cell responses to GAD65 peptides in T1D patients [7], while, in a previous set of experiments, the expansion of the GAD65 (whole molecule) reactive T cells was costimulation dependent in healthy controls, as opposed to T1D patients [8].

Nevertheless, $\mathrm{T}$ cell results were largely inconclusive because autoantigen-specific $\mathrm{T}$ cells in an in vitro expansion could indeed be grown both from patients and controls, as evidenced by 4 International Workshops of the "Immunology Diabetes Society" and by multicenter-blinded control trials, organized under the auspices of the "Immune Tolerance network" [9-11]. Several explanations were put 
forward for justifying these difficulties including [12] their low precursor frequency, the inhability to identify them from the vast excess of $\mathrm{T}$ cells, and their low to moderate affinity to self-antigens.

Cytotoxicity assays, set in vitro, offered proofs that $\mathrm{T}$ lymphocytes are potentially able to kill target cells also in vivo. To this end HLA-A*0201 restricted CD8+ cytotoxic T lymphocytes, specific for a GAD65 decapeptide (114-123), were first detected in PBMC of recent onset T1D patients and in "high-risk" (ICA+) individuals by using the classical ${ }^{\left[{ }^{51} \mathrm{Cr}\right]}$ release cytotoxicity assay [13].

In more recent investigations ELISPOT assays revealed IFN- $\gamma$ production when PBMC from T1D patients were challenged with proinsulin peptides $(30-39 ; 34-42 ; 41-$ 50) [14] and the amyloid polypeptide precursor protein (ppIAPP5-13) peptides [15]. The nonapeptides ppIAPP917, IGRP152-160, and IGRP215-223 from the islet-specific glucose-6-phosphatase catalytic subunit related protein and nonapeptides $172-180$ and 482-490 from the islet autoantigen IA-2 [16] that would bind to and stabilize the HLA-A2 molecules were also identified.

MHC tetramer technology was initially introduced to target antigen-specific CD4+ $\mathrm{T}$ cells in patients with viral, bacterial infections [17], tumors [18]. In reference to human autoimmunity class II tetramers successfully detected GAD65 [19], proinsulin [20], IA-2, and preproinsulin [21] reactive $\mathrm{CD} 4+\mathrm{T}$ cells in PBMC of T1D patients, low percentages of CD4+ $\mathrm{T}$ cells autoreactive to GAD65, the melanocyte differentiation antigen tyrosinase and the testis tumor antigen NY-ESO-1 (epitope 120131) in PBMC of healthy individuals [22], and CD4+ gluten-specific $\mathrm{T}$ cells in PBMC of celiac disease patients [23]. The HLA class I tetramer technology successfully detected circulating CD8+ $\mathrm{T}$ lymphocytes autoreactive to the melan A autoantigen in patients with vitiligo [24], the PBC-E2 autoantigen in patients with primary biliary cirrhosis (PBC) [25], vimentin in patients who were heart transplanted [26], and insulin beta chain nonapeptide (InsB10-18) [27]. In a recent investigation HLA-A*0201 GAD65 (114-122) pentamers detected an increased percentage of autoreactive $\mathrm{T}$ cells in the $\mathrm{CD} 45 \mathrm{RO}+$ subset in T1D patients as compared with controls [28]. In longstanding T1D patients who, after islet transplantation, have a loss of islet allograft and recurrent autoimmunity a high frequency of GAD65-specific T cell clones was found within the expanded autoreactive memory $\mathrm{T}$ cell compartment [29].

In the light of all the aforegoing, we attempted in this preliminary study to device a more sensitive methodology than those currently available for measuring CMI responses and, in particular, GAD65 autoreactive T cells in T1D. Preliminary data indicate that it is possible to implement an assay that still will require appropriate standardization before being used in large scale screening programs. In our protocol, after stimulation of the cells with the GAD65 114122 epitope, we successfully detected a percentage of CD8+ GAD autoreactive $\mathrm{T}$ cells in a sample population including 15 T1D patients ( 9 newly diagnosed and 6 long-standing) by using HLA class I tetramers.

\section{Materials and Methods}

2.1. Patients and Controls. 9 HLA-A* 0201 positive pediatric patients (4 males and 5 females, age of onset range 9.2 years to 16.4 years, mean 12.8 years) were recruited from Lazio region at the onset of T1D at the Unit of Pediatric Endocrine Autoimmune Diseases at the Children's Hospital Bambino Gesù, Rome (Table 1). We also included 6 longterm HLA-A* 0201 positive pediatric T1D patients (between 8 months to 4 years and 5 months after diagnosis). The control population was recruited at the Blood Transfusion Center of our Hospital including 10 HLA-A*0201 positive nondiabetic healthy blood donors. They had no history of autoimmunity and no islet-related autoantibodies were detected in their serum.

2.2. PBMC Isolation. After obtaining informed consent from parents of childrens and normal controls, PBMC were separated by Ficoll-Hypaque (Histopaque, Sigma-Aldrich Chemical C, St Louis, MO, USA) from 5-10 mL sodiumheparinized venous blood samples, washed twice in PBS, and then frozen down in liquid nitrogen.

2.3. HLA-A2 Typing and Subtyping. HLA-A2 typing was initially performed by Flow cytometry analysis and subsequently confirmed by standard allele-specific PCR. In the initial screening, $1 \times 10^{6}$ cells were incubated, for 30 minutes in ice, with an anti-HLA-A2 mouse mAb (1 : 10 dilution, One Lambda, Inc, Canoga Park, CA, USA). After washing by centrifugation at $1500 \mathrm{rpm}$ for 5 minutes at room temperature (RT) in wash buffer $[0,1 \%$ sodium azide, $2 \%$ fetal bovine serum (FBS, Hyclone, South Logan, UT, USA) in PBS], cells were resuspended in the residual volume (approximately $50 \mu \mathrm{L}$ ). $1 \mu \mathrm{L}$ of fluorescent- (FITC-) conjugated goat anti-mouse IgG (Fc $\gamma$ fragment specific antibody) (Jackson ImmunoResearch Laboratories Inc, West Grove, PA, USA) was added. Cells were then incubated in ice for 30 minutes in the dark, washed in wash buffer, and acquired for the analysis in a Becton \& Dickinson FACSCalibur flow cytometer equipped with the Cell Quest software program.

HLA-A2 subtyping was carried out using a molecular system (GenoVision Inc., West Chester, PA, USA); highresolution DNA-based HLA typing of polymorphic class I loci HLA-A, $-\mathrm{B}$, and $-\mathrm{C}$ was also carried out according to a reverse line blot system [30].

2.4. Isolation and Stimulation of PBMC with the GAD65 Peptide. At the time of tetramer assay, cells were thawed and resuspended, at a density of $1 \times 10^{6} / \mathrm{mL}$, in RPMI1640 (GIBCO/BRL, Invitrogen, Gaithersburg, CA, USA), supplemented with $2 \mathrm{mmol} / \mathrm{L}$ L-glutamine, $100 \mu \mathrm{g} / \mathrm{mL}$ penicillin/streptomycin, and 10\% v/v FBS; cells were then cultured in the presence of the GAD65 peptide AA 114-122 (VMNILLQYV) at a concentration of $30 \mu \mathrm{g} / \mathrm{mL}$, for 4 days in 24-well round-bottomed plates (Falcon, Labware BD Biosciences, Oxnard, CA, USA $)\left(1 \times 10^{6}\right.$ cells/well $)$. The GAD65 nonapeptide had been selected for its high affinity binding 
TABLE 1: Sex, age, islet-related autoantibody (IA-2A, IAA and GADA) profile, and associated disorders in 9 newly diagnosed T1D patients at disease onset. The diagnosis of T1D was done according to the WHO and the American Diabetes association (ADA) criteria. NT: not tested; pos: positive; neg: negative.

\begin{tabular}{|c|c|c|c|c|c|c|}
\hline $\begin{array}{l}\text { T1D } \\
\text { patient }\end{array}$ & Sex & $\begin{array}{l}\text { Age at onset } \\
\text { (years) }\end{array}$ & $\begin{array}{c}\text { IA-2A } \\
\text { (cut-off }<1.1)\end{array}$ & $\begin{array}{c}\text { IAA } \\
\text { (cut-off }<7 \%)\end{array}$ & $\begin{array}{c}\text { GADA }^{*} \\
\text { (cut-off <3) }\end{array}$ & Associated disorders \\
\hline 1 & $\mathrm{~F}$ & 10.9 & neg $(0.1)$ & neg (4) & pos (63) & desquamative dermatitis \\
\hline 2 & M & 10.0 & $\operatorname{pos}(28)$ & neg (4) & $\operatorname{pos}(8.6)$ & none \\
\hline 3 & $\mathrm{~F}$ & 14.7 & $\operatorname{pos}(20)$ & $\operatorname{pos}(8)$ & pos (13) & $\begin{array}{l}\text { anti-thyroid antibodies positive, mild } \\
\text { obesity }\end{array}$ \\
\hline 4 & $\mathrm{~F}$ & 12.6 & $\operatorname{pos}(7.9)$ & neg $(4.7)$ & pos (19) & hypercolesterolemia \\
\hline 5 & $\mathrm{M}$ & 9.2 & $\operatorname{pos}(3.6)$ & $\operatorname{pos}(56)$ & neg $(0.1)$ & none \\
\hline 6 & M & 16.4 & $\operatorname{pos}(8)$ & neg (4.7) & neg (2.5) & $\begin{array}{l}\text { autoimmune thyroiditis, LT4 replacement } \\
\text { therapy }\end{array}$ \\
\hline 7 & M & 11.8 & neg $(0.4)$ & $\operatorname{pos}(74)$ & $\operatorname{pos}(5.5)$ & none \\
\hline 8 & $\mathrm{~F}$ & 8.4 & $\operatorname{pos}(1.3)$ & $\operatorname{pos}(11)$ & $\operatorname{pos}(1)$ & none \\
\hline 9 & $\mathrm{~F}$ & 9.4 & $\operatorname{pos}(44)$ & $\operatorname{pos}(16)$ & $\operatorname{pos}(7)$ & anti-thyroid antibodies positive \\
\hline
\end{tabular}

* Assay performed at San Raffaele Hospital, Milan, Italy. GADA and IA-2A measurements were performed by radiobinding assay with in vitro translated ${ }^{35}$ Smethionine-labeled GAD65 or IA-2 [31, 32]. IAA were measured using a competitive protein A/G insulin radiobinding assay [33].

to HLA A*0201 in an HLA peptide motif search Database (http://www-bimas.cit.nih.gov/molbio/hla_bind). In parallel experiments control cell cultures were set up by incubating PBMC from the same individual with IL-2 $(25 \mathrm{IU} / \mathrm{mL}$, Sigma) for 4 days, in place of the GAD65 peptide, in order to ensure that PBMC would live for the entire culture period prior to the flow cytometry analysis (vide infra). At the end of the 4 days, PBMC, either stimulated with the GAD65 peptide or incubated with IL-2, were washed in calcium-magnesium free Dulbecco's phosphate-buffered saline 1X (Euroclone, Wethersby, West York, UK), by centrifugation at $1500 \mathrm{rpm}$ for 5 minutes at RT. This washing was introduced to remove the excess of GAD65 peptide and IL-2 from the culture, so to maximally reduce the risk of nonspecific binding, when PBMC will subsequently be stained with labeled tetramers. The two sets of PBMC were cultured for additional two days with IL-2 $(25 \mathrm{IU} / \mathrm{mL})$ in the same medium (RPMI-1640, $2 \mathrm{mmol} / \mathrm{l} \mathrm{L}$-glutamine, $100 \mu \mathrm{g} / \mathrm{mL}$ penicillin/streptomycin, $10 \% \mathrm{v} / \mathrm{v}$ FBS).

2.5. HLA-A*0201 Peptide-Tetramers. Phycoerythrin (PE) labeled tetramers were generated, using either the GAD65 peptide (VMNILLQYV) or the Flu peptide (GILGFVFTL) [34], known to have a high-affinity binding with HLAA*0201 (purchased from ProImmune Limited, Oxford, UK).

2.6. Cell Staining with HLA A*0201/GAD65 Peptide Tetrameric Complexes. On day 6, approximately $5 \times 10^{5}$ cells, stimulated with the GAD65 peptide or cultured with IL-2, were allocated for staining conditions. Cells were washed by centrifugation at $1500 \mathrm{rpm}$ for 5 minutes at RT in wash buffer $(0.1 \%$ sodium azide, $2 \%$ FBS in PBS) and resuspended in the residual volume (approximately $50 \mu \mathrm{L}$ ). $1 \mu \mathrm{L}$ of phycoerithrin (PE) labeled GAD65 peptide (VMNILLQYV) tetramer was added to each cell preparation and incubated in ice for 30 minutes in the dark, then washed in wash buffer. $1 \mu \mathrm{L}$ of mAb anti-human CD8 (FITC labelled
(Becton \& Dickinson, Pharmingen, San Diego, CA, USA)) and $5 \mu \mathrm{L}$ of mAb anti-human CD3 [allophycocyanin (APC) labelled (Becton \& Dickinson)] were added for further staining the different cell preparations. In alternative for CD8 staining, $1 \mu \mathrm{L}$ of biotinylated $\mathrm{mAb}$ anti-human CD8 ( $1: 10$, Becton Dickinson) was used followed by streptavidin cychrome (Cys5) conjugate (1:10, Southern Biotechnology, Birmingham, AL, USA). Cells were incubated in ice for at least 30 minutes in the dark, washed twice in wash buffer, and then immediately acquired for the analysis in a Beckton \& Dickinson FACSCalibur flow cytometer and CellQuest software program.

\subsection{Tetramer Assay Controls}

2.7.1. Sensitivity of the Tetramer Assay. In order to verify the sensitivity of the HLA-A*0201 tetramer assay, the Flu nonapeptide (GILGFVFTL) was used to stimulate PBMC of one HLA-A $* 201$ normal individual. This test was performed in order to verify that we could obtain an increased sensitivity of the Flu tetramer staining after Flu peptide stimulation. The staining with the Flu tetramer was carried out either by direct assay ex vivo or after stimulation of the same PBMC first with the Flu peptide $(3.5 \mu \mathrm{g} / \mathrm{mL})$ for 4 days followed, after washing the cells, by an incubation with IL-2 for 2 days.

2.7.2. Positive Stimulation Controls. A positive control of stimulation was introduced in all the experiments in order to prove that in vitro stimulation worked in all subjects, including those from whom no GAD specific $\mathrm{T}$ cells were detected. The presence of Flu tetramer positive cells was assessed in randomly selected samples by staining after Flu peptide stimulation.

2.7.3. Specificity of the Tetramer Binding. In order to verify the specificity of the reactivity of the GAD65 HLA A*0201 tetramer in the detection of GAD65 nonapeptide reactive $\mathrm{T}$ cells and as control of nonspecific binding, PBMC of 
randomly selected T1D patients and controls were cultured separately with the GAD65 nonapeptide, the Flu nonapeptide, and IL-2. The Flu and GAD65 nonapeptides were used at the same concentration $(10-30 \mu \mathrm{g} / \mathrm{mL})$. After 4 days, PBMC, cultured in the 3 different conditions, were washed and subsequently incubated with IL-2 alone for an additional 2 days. Cells were then recovered, washed, and stained with the GAD65 nonapeptide HLA A*0201 tetramers and analyzed by flow cytometry.

2.8. Statistical Analysis and Cutoff Extimation. Differences in the percentages of $\mathrm{CD} 3+/ \mathrm{CD} 8+/ \mathrm{GAD} 65$ reactive $\mathrm{T}$ cells between normal controls and T1D patients in each (IL-2 and GAD65 peptide) stimulated PBMC populations were assessed by Mann-Whitney-U test. Variations in the response of PBMC, either treated with IL-2 or stimulated with the GAD65 peptide within each group (i.e., controls versus T1D patients), were evaluated by Wilcoxon's test. A $P$ value less than .05 was considered as significant.

\section{Results}

3.1. Selection of HLA-A*0201 Restricted High-Affinity Binder GAD65 Epitope. It is well known that HLA class I molecules bind peptides 8-10 aminoacids long, but preferentially nonapeptides $[35,36]$. After database search for nonamers of the GAD65 protein sequence (P48320, NCBI Database), we selected peptide GAD65 114-122, on the basis of its high score of affinity binding (1080.239) to HLA-A*0201.

\subsection{GAD65-Specific CD8+ T Cells in PBMC of Normal controls and T1D patients are Identified by HLA Class I Tetramer Staining}

3.2.1. Detection of Flu Reactive T Cells in Normal Controls. Direct staining ex vivo with HLA A*0201 Flu peptide tetramers of PBMC of a normal HLA A*0201 positive individual detected $0.03 \%$ of $\mathrm{CD} 3+/ \mathrm{CD} 8+/$ Flu reactive $\mathrm{T}$ cells. The percentage increased to $0.23 \%$, when PBMC of the same individual were first stimulated for 4 days with the same Flu peptide (data not shown).

\subsubsection{Detection of GAD65 Peptide Reactive T Cells}

Normal Controls. In PBMC of normal individuals no significant variations were found in the percentage of $\mathrm{CD}^{+} / \mathrm{CD}^{+} / \mathrm{GAD} 65$ reactive $\mathrm{T}$ cells between PBMC cultured with either IL-2 or the GAD65 peptide (MannWithney test versus PBMC IL-2 treated $P=.05$, Figure 1 ).

TD Patients. In PBMC of T1D patients the percentage of CD3+/CD8+/GAD65 reactive T cells were significantly more pronounced in comparison to those registered with PBMC of controls after stimulation with the same GAD65 peptide $(P=.001$ T1D versus controls, Figures 1 and 2$)$.

Figure 2 shows PBMC of a representative T1D patient treated with IL-2 (panel (a), (b), (c)) and with GAD65 peptide (panel (d), (e), (f)). The analysis was conducted



Figure 1: Statistical analysis of the percentages of CD3+/CD8+/ GAD65 peptide autoreactive T cells in PBMC of normal controls $(n=10)$ and T1D patients $(n=15)$. In PBMC of T1D patients, cultured with IL-2 alone for $4+2$ days, the median of $\mathrm{CD}^{+} / \mathrm{CD}^{+} / \mathrm{GAD} 65$ reactive $\mathrm{T}$ cells was 0.70 [interquartile range (0.22-1.19); range (0.00-4.3)], while when cultured with the GAD65 peptide for 4 days and IL-2 for additional 2 days, the median was 0.81 [interquartile range (0.50-4.04); range (0.1415.6)] (Mann-Whitney U Test PBMC GAD65 peptide stimulated versus PBMC IL-2 treated, $P=.03$; Wilcoxon's Test PBMC of T1D patients versus PBMC of controls, both cultured with IL-2, $P=.07$; Wilcoxon's Test PBMC of T1D patients versus PBMC of controls, both stimulated with GAD65 peptide, $P=.001$ ).

only in $\mathrm{R} 1$ region (living cells as evidenced by morphological parameters) and in the $\mathrm{R} 2$ region $(\mathrm{CD} 3+/ \mathrm{CD} 8+$ cells). The population of $\mathrm{CD} 3+/ \mathrm{CD} 8+/ \mathrm{GAD} 65$ reactive cells was shown in panel (f) (4.04\% of total cell population).

IL-2 treatment affected differentially the detection of CD3+/CD8+/GAD65 reactive T cells in T1D patients versus control $(P=.07$ T1D patients versus controls) (Figure 1).

Specificity of the GAD65 Peptide Response. The percentage of CD3+/CD8+/GAD65 reactive T cells estimated in PBMC of single patients after GAD65 peptide stimulation was higher than after Flu peptide stimulation or when cultured with IL-2 alone (data not shown). With PBMC of the normal controls, the percentage of $\mathrm{CD}^{+} / \mathrm{CD}^{+} / \mathrm{GAD} 65$ reactive $\mathrm{T}$ cells was comparable in the 3 stimulation conditions. In principle, we assume that the specific reactivity could be detectable in each single sample only after GAD65 peptide stimulation. This test is an alternative to control the nonspecific binding of tetramer to $\mathrm{T}$ cells with the use of an irrelevant peptide.

\section{Discussion}

Tetramers containing autoantigenic peptides have clinical utility in autoimmunity for diagnostic and, potentially, therapeutic applications [19-29]. Previous studies $[19,20]$ 


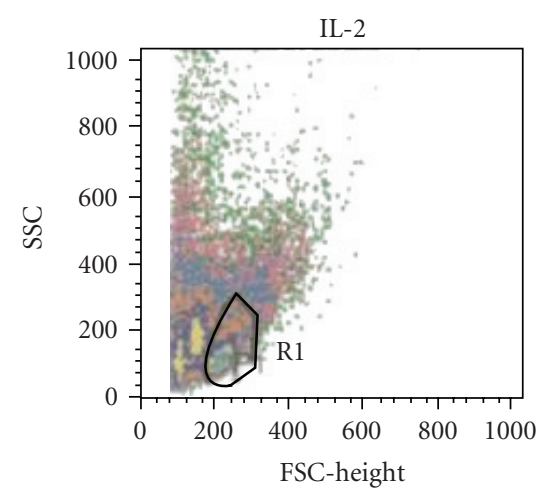

(a)

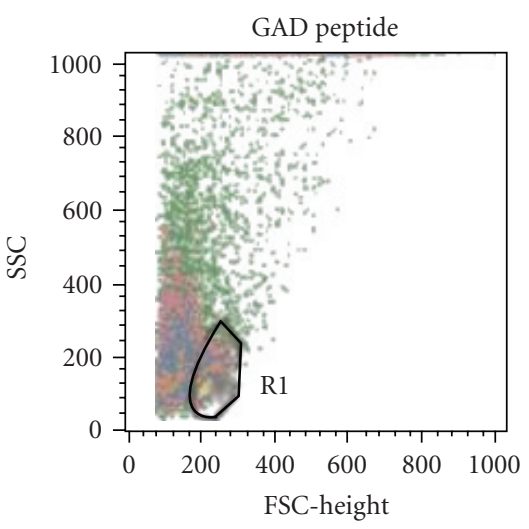

(d)

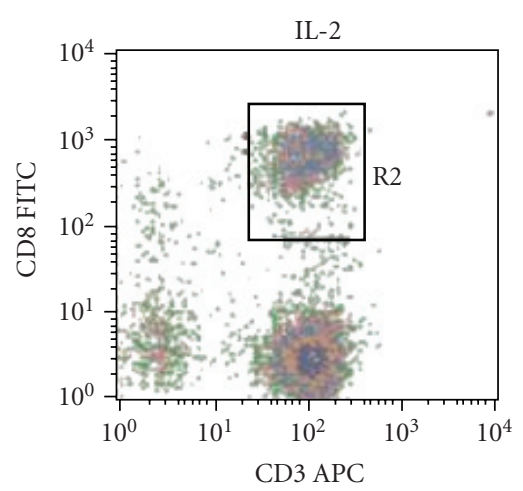

(b)

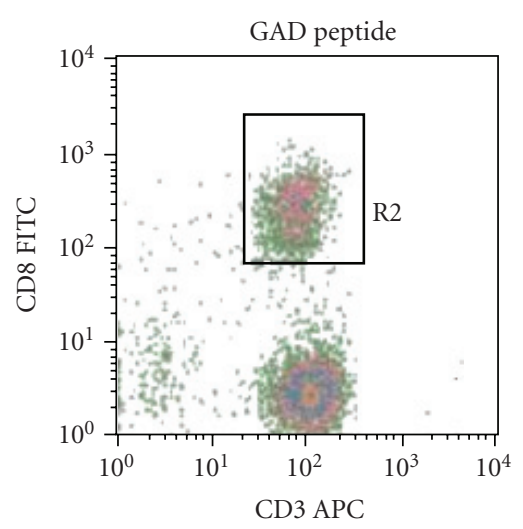

(e)

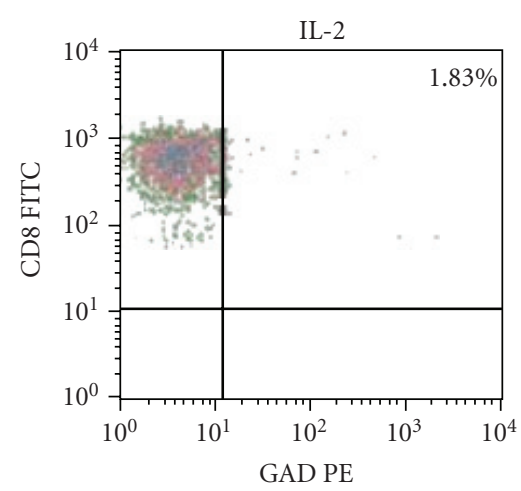

(c)

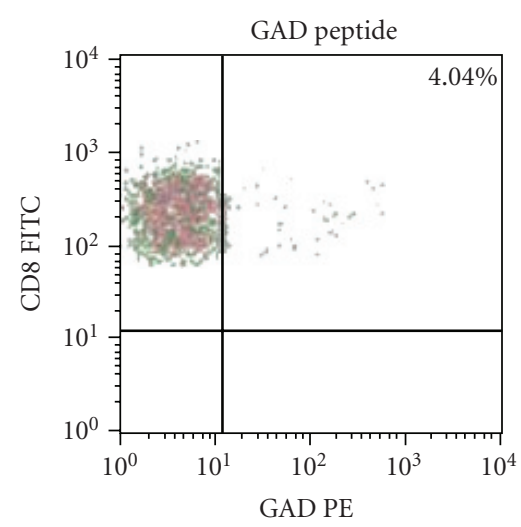

(f)

FIGURE 2: Density plots of cytometric analysis of PBMC of one representative T1D patient at day 6 of culture. (a), (b), (c) Cells stimulated with IL-2; (d), (e), (f) cells stimulated with the GAD65 peptide. (a), (d) Density Plots of morphological parameters (FSC-H; SSC-H) of cells treated with IL-2 and GAD65, respectively. In gate R1 cells were selected by morphological parameters as living cells. In the subsequent panels ((b), (c), (e), (f)) only this region was considered. ((b), (e)) Density Plots of CD3 APC and CD8 FITC cells, treated with IL-2 and GAD65 peptide, respectively. Positive CD3/CD8 cells were selected in R2 gate. In (c) and (f) panel only R2 gate was considered and the percentage in the upper right quadrant represented $\mathrm{CD} 3+/ \mathrm{CD} 8+/ \mathrm{GAD} 65$ reactive $\mathrm{T}$ lymphocytes.

clearly demonstrated that MHC class II tetramers can efficiently detect GAD65 reactive CD4+ T cells in PBMC of T1D patients. GAD65-specific HLA DR0401-restricted clones could be even derived from a diabetic patient using tetramers as stimulating agent. GAD65 tetramers could also deliver activation signals in the generated clones [33].

These encouraging data prompted us to trace GAD65 autoreactive $\mathrm{T}$ cells in T1D; in the present investigation HLA-A*0201 tetramers were therefore constructed with a "natural" peptide (GAD65 (AA114-122), half-time disassociation 1080,239). This peptide has been used in previous class I tetramer investigations $[28,29]$ and now employed to establish a more sensitive assay. We could have chosen the GAD65 decamer (AA114-123) [13] but the peptide ranked low in the affinity binding scale (half time disassociation, 35.012). In addition, the terminal valine in position 122 seems to be relevant for the antigenic presentation of the motif, as the very low-affinity binding of the nonapeptide $115-123$ to HLA $A^{*} 0201$ (half time disassociation, 0.316) demonstrates. We argue against the use of "modified" peptides for assembling tetramers [24] employed in previous investigations in order to increase their affinity binding to the tetramer.

There have been two ways of performing HLA class I tetramer assays. The first is by direct ex vivo staining with labeled peptide/tetramer complexes [24]; in the second method PBMC are preincubated and stimulated with the peptide and then stained with the labeled peptide/tetramer or pentamer complexes [25-29]. We have chosen the second approach, because we believe that preincubation with the peptide might induce a limited specific $\mathrm{T}$ cell expansion in vitro and, therefore, may increase the chance to "awake" autoreactive CD8+ T cells.

Novel steps in the experimental procedure were designed as follows: (1) a reduced period of antigen-specific cell expansion (4 days rather than 21 days [27], 28 days [26], 10 days [28], time course selected in other HLA class I tetramer assays); (2) an intermediate washing step after cells were stimulated with the GAD65 nonapeptide; (3) a 2-day incubation with IL-2 in the absence of the GAD65 nonapeptide; and (4) a final washing step, before staining the cells with the labeled tetramers. In addition, we relied only on the autologous APCs, present in the pool of the PBMC, not 
prepulsed with the nonapeptide, as it was done in previous assays [27], and we set up parallel PBMC cultures either with IL-2 alone, an internal cell culture control. The short period of peptide stimulation has the advantage that cultures are terminated before clonal expansion and/or "in vitro" cell differentiation can occur. We need also to underline that the possibility of testing frozen/defrosted PBMC is of paramount importance when planning large retrospective epidemiological investigations.

By applying these novel experimental conditions, the recovery of $\mathrm{CD} 3+/ \mathrm{CD} 8+/ \mathrm{GAD} 65$ reactive $\mathrm{T}$ cells in $\mathrm{T} 1 \mathrm{D}$ patients ranged from $0.5 \%$ to $15.6 \%$ after GAD65 peptide stimulation of PBMC. To our knowledge, this is the highest percentage of autoreactive $\mathrm{CD} 8^{+} \mathrm{T}$ cells ever "captured" by HLA class I tetramers in PBMC of patients with a human autoimmune disease $(0,1 \%$ to $1 \%$ in vitiligo [24] $4,2 \%$ in heart transplantation [26]; up to $0.4 \%$ of CD8+ CD45RO+ $\mathrm{T}$ cells in newly diagnosed T1D patients [28]; between $2.6 \%$ and $8.3 \%$ within the Ki- $67+\mathrm{CD} 8+$ cell fraction $(1.65 \%+/-$ $0.25 \%$ of the total CD $8+$ lymphocytes) in islet transplanted T1D patients [29]).

\section{Conclusions}

We set up a feasible assay that will now require an appropriate standardisation. This can be achieved by testing PBMC of a large number of T1D patients, normal controls, and especially prediabetic high-risk individuals. A valid statistical evaluation of results will help to establish an appropriate cutoff value of positivity in the assay.

\section{Acknowledgments}

The authors acknowledge Dr. R. Carsetti and Dr. E. Giorda of the Flow Cytometry Unit OPBG for assistance in flow cytometry investigation, Dr. D. Fruci of the Research Laboratories OPBG for helpful discussion, Dr. P. Giustiniani of the Blood Transfusion Center OPBG for HLA typing and subtyping, Dr. R Buzzetti of La Sapienza University for HLA subtyping, and Dr. V. Di Ciommo of the Epidemiology Department OPBG for statistical analysis. This work was supported by the Italian Ministry of Health.

\section{References}

[1] A. Fierabracci and G. F. Bottazzo, "The continuous discovery of autoantigens in endocrine organ-specific autoimmunity: do they help us to understand pathogenesis?" Springer Seminars in Immunopathology, vol. 24, no. 3, pp. 243-259, 2002.

[2] B. O. Roep, "The role of T-cells in the pathogenesis of type 1 diabetes: from cause to cure," Diabetologia, vol. 46, no. 3, pp. 305-321, 2003.

[3] S. Arif, T. I. Tree, T. P. Astill, et al., "Autoreactive T cell responses show proinflammatory polarization in diabetes but a regulatory phenotype in health," Journal of Clinical Investigation, vol. 113, no. 3, pp. 451-463, 2004.

[4] P. A. Ott, B. R. Berner, B. A. Herzog, et al., "CD28 costimulation enhances the sensitivity of the ELISPOT assay for detection of antigen-specific memory effector CD4 and CD8 cell populations in human diseases," Journal of Immunological Methods, vol. 285, no. 2, pp. 223-235, 2004.
[5] P. A. Ott, B. A. Herzog, S. Quast, et al., "Islet-cell antigenreactive $\mathrm{T}$ cells show different expansion rates and Th1/Th2 differentiation in type 1 diabetic patients and healthy controls," Clinical Immunology, vol. 115, no. 1, pp. 102-114, 2005.

[6] B. M. Brooks-Worrell, R. Juneja, A. Minokadeh, C. J. Greenbaum, and J. P. Palmer, "Cellular immune responses to human islet proteins in antibody-positive type 2 diabetic patients," Diabetes, vol. 48, no. 5, pp. 983-988, 1999.

[7] P. A. Ott, M. T. Dittrich, B. A. Herzog, et al., "T cells recognize multiple GAD65 and proinsulin epitopes in human type 1 diabetes, suggesting determinant spreading," Journal of Clinical Immunology, vol. 24, no. 4, pp. 327-339, 2004.

[8] V. Viglietta, S. C. Kent, T. Orban, and D. A. Hafler, "GAD65reactive $\mathrm{T}$ cells are activated in patients with autoimmune type 1a diabetes," Journal of Clinical Investigation, vol. 109, no. 7, pp. 895-903, 2002.

[9] M. Peakman, T. I. Tree, J. Endl, P. van Endert, M. A. Atkinson, and B. O. Roep, "Characterisation of preparations of GAD65, proinsulin, and the islet tyrosine phosphatase IA-2 for use in detection of autoreactive T-cells in type 1 diabetes: report of phase II of the Second International Immunology of Diabetes Society Workshop for Standardization of T-cell assays in type 1 diabetes," Diabetes, vol. 50, no. 8, pp. 1749-1754, 2001.

[10] B. O. Roep, M. A. Atkinson, P. M. van Endert, P. A. Gottlieb, S. B. Wilson, and J. A. Sachs, "Autoreactive T cell responses in insulin-dependent (type 1) diabetes mellitus. Report of the first international workshop for standardization of T cell assays," Journal of Autoimmunity, vol. 13, no. 2, pp. 267-282, 1999.

[11] N. C. Schloot, G. Meierhoff, and M. K. Faresjö, "Comparison of cytokine ELISpot assay formats for the detection of islet antigen autoreactive T cells: report of the third immunology of diabetes society T-cell workshop," Journal of Autoimmunity, vol. 21, no. 4, pp. 365-376, 2003.

[12] B. O. Roep, "Autoreactive T cells in endocrine/organ-specific autoimmunity: why has progress been so slow?" Springer Seminars in Immunopathology, vol. 24, no. 3, pp. 261-271, 2002.

[13] P. Panina-Bordignon, R. Lang, P. M. van Endert, et al., "Cytotoxic T cells specific for glutamic acid decarboxylase in autoimmune diabetes," Journal of Experimental Medicine, vol. 181, no. 5, pp. 1923-1927, 1995.

[14] A. Toma, S. Haddouk, J.-P. Briand, et al., "Recognition of a subregion of human proinsulin by class I-restricted T cells in type 1 diabetic patients," Proceedings of the National Academy of Sciences of the United States of America, vol. 102, no. 30, pp. 10581-10586, 2005.

[15] C. Panagiotopoulos, H. Qin, R. Tan, and C. B. Verchere, "Identification of a beta-cell-specific HLA class I restricted epitope in type 1 diabetes," Diabetes, vol. 52, no. 11, pp. 26472651, 2003.

[16] Q. Ouyang, N. E. Standifer, H. Qin, et al., "Recognition of HLA class I-restricted $\beta$-cell epitopes in type 1 diabetes," Diabetes, vol. 55, no. 11, pp. 3068-3074, 2006.

[17] G. T. Nepom, "MHC multimers: expanding the clinical toolkit," Clinical Immunology, vol. 106, no. 1, pp. 1-4, 2003.

[18] C. Maczek, T. G. Berger, B. Schuler-Thurner, et al., "Differences in phenotype and function between spontaneously occurring melan-A, tyrosinase- and influenza matrix peptidespecific CTL in HLA-A* 0201 melanoma patients," International Journal of Cancer, vol. 115, no. 3, pp. 450-455, 2005.

[19] H. Reijonen, E. J. Novak, S. Kochik, et al., "Detection of GAD65-specific T-cells by major histocompatibility complex class II tetramers in type 1 diabetic patients and at-risk subjects," Diabetes, vol. 51, no. 5, pp. 1375-1382, 2002. 
[20] V. Öling, J. Marttila, J. Ilonen, et al., "GAD65- and proinsulinspecific $\mathrm{CD}^{+}{ }^{+} \mathrm{T}$-cells detected by MHC class II tetramers in peripheral blood of type 1 diabetes patients and at-risk subjects," Journal of Autoimmunity, vol. 25, no. 3, pp. 235-243, 2005.

[21] J. Yang, N. Danke, M. Roti, et al., "CD4 ${ }^{+}$T cells from type 1 diabetic and healthy subjects exhibit different thresholds of activation to a naturally processed proinsulin epitope," Journal of Autoimmunity, vol. 31, no. 1, pp. 30-41, 2008.

[22] N. A. Danke, D. M. Koelle, C. Yee, S. Beheray, and W. W. Kwok, "Autoreactive T cells in healthy individuals," Journal of Immunology, vol. 172, no. 10, pp. 5967-5972, 2004.

[23] M. Ráki, L.-E. Fallang, M. Brottveit, et al., "Tetramer visualization of gut-homing gluten-specific T cells in the peripheral blood of celiac disease patients," Proceedings of the National Academy of Sciences of the United States of America, vol. 104, no. 8, pp. 2831-2836, 2007.

[24] G. S. Ogg, P. R. Dunbar, P. Romero, J. L. Chen, and V. Cerandolo, "High frequency of skin-homing melanocytespecific cytotoxic T lymphocytes in autoimmune vitiligo," The Journal of Experimental Medicine, vol. 188, no. 6, pp. 1203 1208, 1998.

[25] H. Kita, S. Matsumura, X.-S. He, et al., "Quantitative and functional analysis of PDC-E2-specific autoreactive cytotoxic $\mathrm{T}$ lymphocytes in primary biliary cirrhosis," The Journal of Clinical Investigation, vol. 109, no. 9, pp. 1231-1240, 2002.

[26] L. D. Barber, A. Whitelegg, J. A. Madrigal, N. R. Baner, and M. L. Rose, "Detection of vimentin-specific autoreactive $\mathrm{CD} 8^{+} \mathrm{T}$ cells in cardiac transplant patients," Transplantation, vol. 77, no. 10, pp. 1604-1609, 2004.

[27] G. G. Pinkse, C. Boitard, T. I. Tree, M. Peakman, and B. O. Roep, "HLA class I epitope discovery in type 1 diabetes. Independent and reproducible identification of proinsulin epitopes of CD8 T cells-Report of the IDS T cell workshop committee," Annals of the New York Academy of Sciences, vol. 1079, pp. 19-23, 2006.

[28] P. Monti, M. Scirpoli, A. Rigamonti, et al., "Evidence for in vivo primed and expanded autoreactive $\mathrm{T}$ cells as a specific feature of patients with type 1 diabetes," Journal of Immunology, vol. 179, no. 9, pp. 5785-5792, 2007.

[29] P. Monti, M. Scirpoli, and P. Maff, "Islet transplantation in patients with autoimmune diabetes induces homeostatic cytokines that expand autoreactive memory T cells," Journal of Clinical Investigation, vol. 118, no. 5, pp. 1806-1814, 2008.

[30] R. Buzzetti, A. Galgani, and A. Petrone, "Genetic prediction of type 1 diabetes in a population with low frequency of HLA risk genotypes and low incidence of the disease (the DIABFIN study)," Diabetes/Metabolism Research and Reviews, vol. 20, no. 2, pp. 137-143, 2004.

[31] E. Bonifacio, V. Lampasona, S. Genovese, M. Ferrari, and E. Bosi, "Identification of protein tyrosine phosphatase-like IA2 (islet cell antigen 512) as the insulin-dependent diabetesrelated 37/40 autoantigen and a target of islet-cell antibodies," Journal of Immunology, vol. 155, no. 11, pp. 5419-5426, 1995.

[32] E. Bonifacio, S. Genovese, S. Braghi, et al., "Islet autoantibody markers in IDDM: risk assessment strategies yielding high sensitivity," Diabetologia, vol. 38, no. 7, pp. 816-822, 1995.

[33] H. E. Naserke, N. Dozio, A. G. Ziegler, and E. Bonifacio, "Comparison of a novel microassay for insulin autoantibodies with the conventional radiobinding assay," Diabetologia, vol. 41, no. 6, pp. 681-683, 1998.

[34] H.-G. Zhang, X.-W. Pang, X.-Y. Shang, Q. Xing, and W.-F. Chen, "Functional supertype of HLA-A2 in the presentation of Flu matrix p58-66 to induce $\mathrm{CD}^{+} \mathrm{T}$-cell response in a
Northern Chinese population," Tissue Antigens, vol. 62, no. 4, pp. 285-295, 2003.

[35] G. F. Bottazzo, M. Locatelli, A. Fierabracci, and D. Fruci, "The genetic basis of immune and autoimmune responses," Acta Paediatrica, vol. 93, no. 445, pp. 38-42, 2004.

[36] P. A. Wearsch and P. Cresswell, "The quality control of MHC class I peptide loading," Current Opinion in Cell Biology, vol. 20, no. 6, pp. 624-631, 2008. 


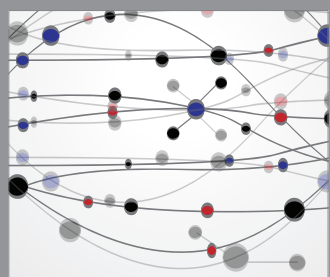

The Scientific World Journal
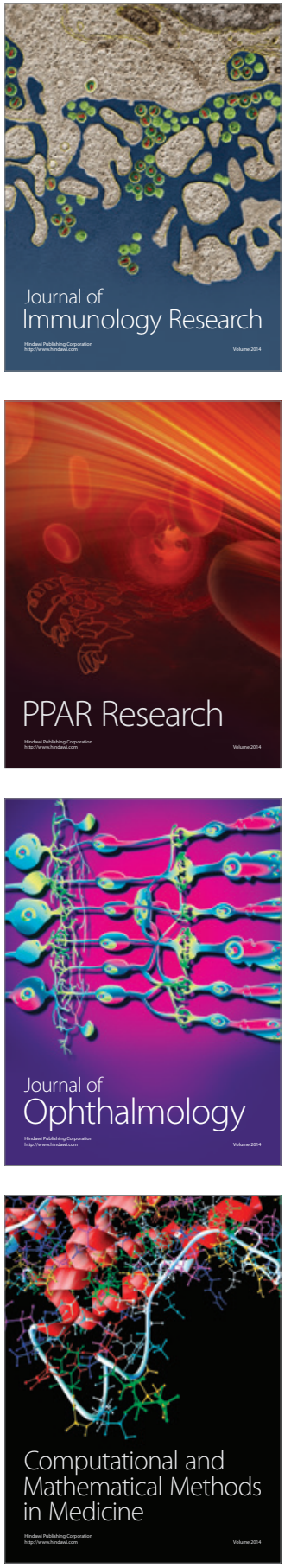

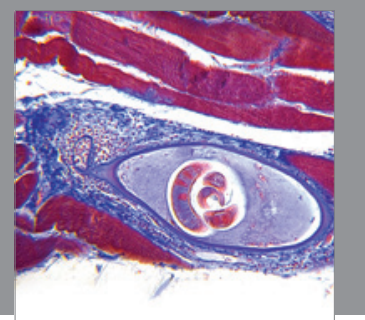

Gastroenterology

Research and Practice
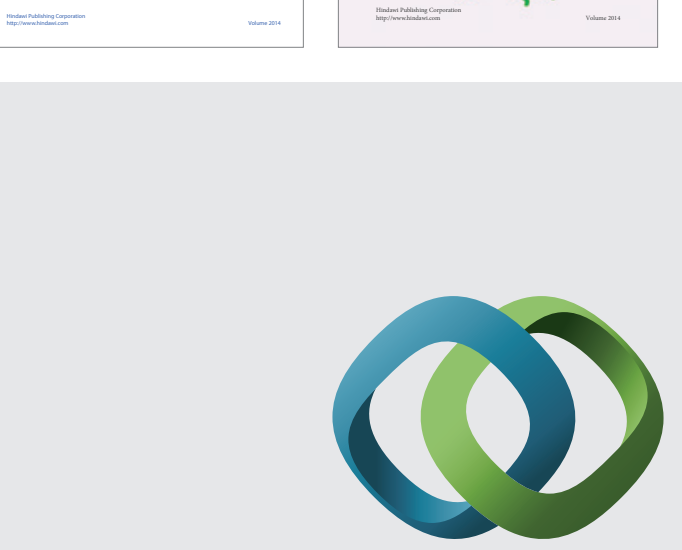

\section{Hindawi}

Submit your manuscripts at

http://www.hindawi.com


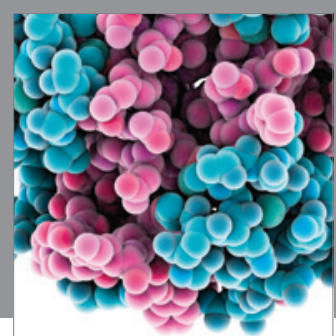

Journal of
Diabetes Research

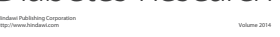

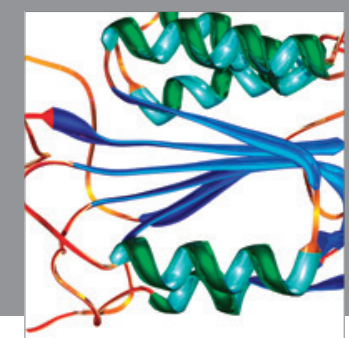

Disease Markers
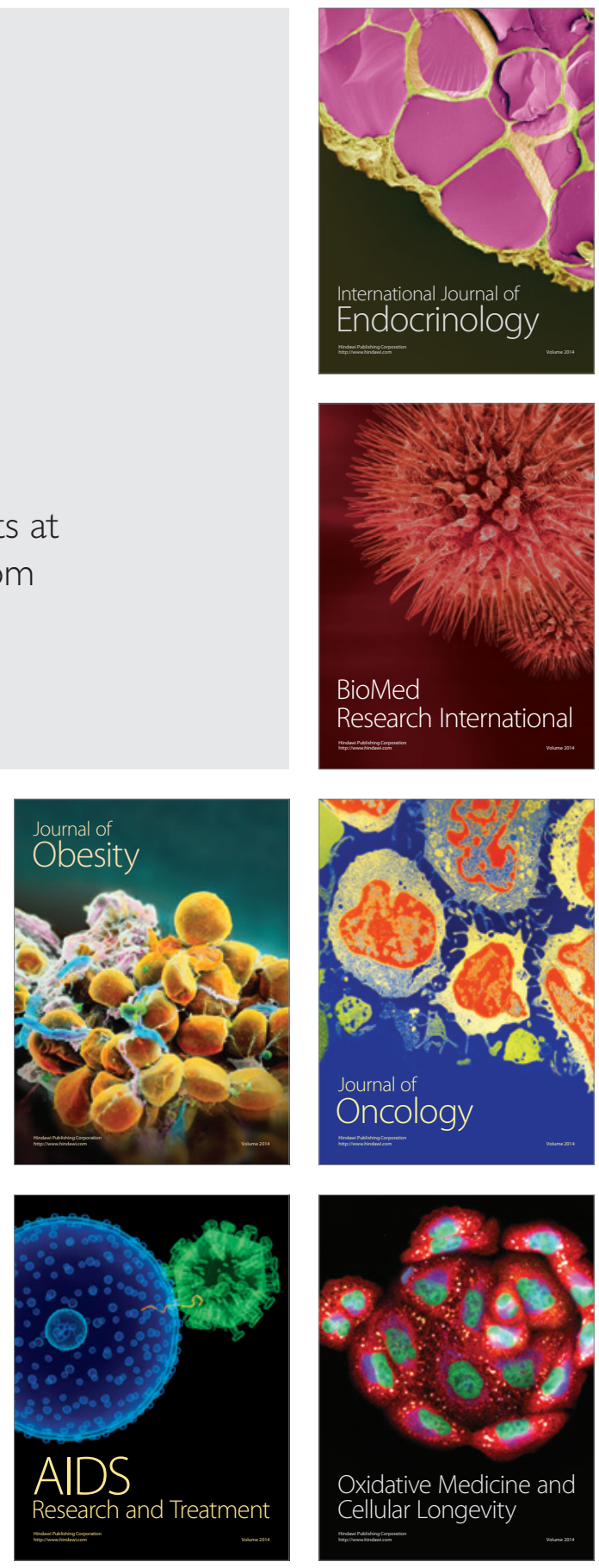